\title{
A Community Intervention to Decrease Antibiotics Used for Self-Medication Among Latino Adults
}

\author{
Arcb G. Mainous III, PbD \\ Vanessa A. Diaz, MD, MS \\ Mark Carnemolla, BS \\ Department of Family Medicine, Medical \\ University of South Carolina, Charleston, \\ South Carolina
}

\begin{abstract}
PURPOSE Recent evidence in Latino communities indicates substantial self-medication with antibiotics obtained without a prescription (WORx). We implemented and evaluated a culturally sensitive educational intervention to decrease antibiotic self-medication.

METHODS We conducted a community-based intervention with preintervention and postintervention measures in the intervention community (Charleston, South Carolina) as well as a postintervention measure in a control community (Greenville, South Carolina) 200 miles away. The 9-month culturally sensitive intervention included multiple media sources (pamphlets, radio, newspapers). We evaluated the use of antibiotics WORx in the United States, as well as the likelihood of importing antibiotics, by surveying Latino adults in the intervention $(n=250)$ and in the control community $(n=250)$.
\end{abstract}

RESULTS Most adults in the intervention community (69\%) and the control community $(60 \%)$ reported some exposure to messages about the inappropriate use of antibiotics, and $25.9 \%$ in the intervention community and $8.6 \%$ in the control community reported seeing our patient education pamphlets. A substantial proportion of Latino adults in both the intervention (31\%) and control communities (20\%) have obtained antibiotics WORx in the United States. In multivariate analyses, exposure to an educational message was not a significant predictor of having acquired antibiotics WORx in the United States in past 12 months. The primary predictor of respondents' having acquired antibiotics WORx in the United States was whether they had bought antibiotics WORx outside the United States.

CONCLUSIONS Novel approaches are needed to decrease the use of antibiotics WORx in Latino communities, as focusing only on education may not be sufficient to change behaviors common in their home countries.

Ann Fam Med 2009;7:520-526. doi:10.1370/afm.1061.

\section{INTRODUCTION}

ntibiotic resistance is a global problem with a strong impact on
morbidity and mortality. ${ }^{1-4}$ Excessive use of antibiotics contributes
to antibiotic resistance. ${ }^{5,6}$ Consequently, reducing inappropriate use is key to many resistance initiatives, most of which focus on controlling prescribing by health care clinicians. ${ }^{1,4}$ This strategy does not address self-medication with antibiotics, which occurs in many countries but is particularly problematic where the use of antibiotics without a prescription (WORx) is encouraged by no or lax laws restricting antibiotic sales. ${ }^{7-9}$ These issues are particularly challenging in Latin America. ${ }^{10,11}$

Recent evidence from Latino communities of South Carolina and New York indicate self-medication with antibiotics WORx is common, with the drugs either obtained in a foreign country and imported into the United States or acquired in the United States. ${ }^{12-15}$ The Latino population has 
historically been concentrated in certain metropolitan areas, such as New York and Los Angeles, and the southwestern United States. More recently this population has dispersed to states with smaller cities or more rural areas, such as South Carolina. The goal of this project was to implement and evaluate a culturally sensitive educational intervention to decrease self-medication with antibiotics in the Latino community.

\section{METHODS}

\section{Design}

We implemented a community-based intervention. A survey of the Latino community in the Charleston, South Carolina, in 2004 was used as a pretest. ${ }^{12} \mathrm{We}$ implemented the intervention in Charleston in 2007 and early 2008. After the intervention we conducted a survey of the Charleston Latino community and in a comparison area (Greenville, South Carolina) in 2008 that did not receive the intervention. The measures and questions used in the 2004 survey were reused in 2008. Greenville is more than 200 miles from Charleston and functioned as a control community because the intervention was not disseminated in Greenville.

\section{Intervention}

A series of focus groups, with members of the Latino community to assess factors that contribute to inappropriate use of antibiotics, was used to develop the educational intervention. ${ }^{13}$ Findings in the focus groups indicated that Latinos may prefer to bypass the medical provider and instead directly obtain medication from a supplier within their community. Accordingly, educational messages tailored to the conventional health care process are likely to be ineffective. Based on this information indicating specific cultural beliefs regarding self-medication with antibiotics, we created patient education pamphlets and public service advertisements for Spanish-language newspapers. The educational initiative, entitled "Solo Con Receta," meaning "only with a prescription," focused on the risks involved in self-medication and the benefits of receiving a diagnosis and treatment recommendations from the formal health sector.

Our educational intervention was multifaceted and focused on 3 points of dissemination: community sites, newspaper, and radio. We distributed more than 1,000 pamphlets in quantities of 15 to 60 at 34 community sites (physician offices, churches, English as a second language classes, Mexican restaurants, and Mexican food stores). We placed 3 -inch by 5 -inch advertisements with the heading Solo Con Receta and a bulleted message in 2 different Spanish language newspapers for 3 months each. A member of our team broadcast 2-hour programs focused on antibiotic use, resistance, and risks of self-medication on a monthly local Spanish-language radio health show.

The intervention lasted from July 2007 to March 2008 and occurred only in the greater Charleston area. The Spanish-language newspapers were not distributed in the control area of Greenville, and the radio station did not broadcast to Greenville, thereby decreasing potential contamination by the intervention. This study received Institutional Review Board approval from the Medical University of South Carolina.

\section{Participants and Data Collection}

Self-identified Latinos adults (aged 18 years or older) were recruited in Charleston, South Carolina, area and in Greenville, South Carolina. Data were collected between April and June 2008. Our focus group data suggested that many individuals would self-medicate without going to the doctor, so collecting data in health care settings may not yield the necessary crosssection of the Latino population. ${ }^{16}$

Because there was no census listing of eligible individuals, we used a site-based sampling method to recruit a representative sample, a strategy commonly used to access hard-to-reach populations. ${ }^{17,18}$ Briefly, this approach is based on the idea that every resident is a member of at least 1 group, or site. Sites can include, but are not limited to, trailer parks, migrant camps, community centers, and church congregations. Sites are then chosen, and respondents are selected from a variety of sites. The resulting sample should reflect the variability in the community. Other studies of Latinos have used similar methods and recruited individuals from health clinics, social service agencies, community centers, work sites, and public venues that have a large number of Latinos. ${ }^{19-21}$

Interviewers were Latino immigrants to the United States and bilingual. The interviewers went to locations with high concentrations of Latinos using the venues and strategies detailed above. Participants received an explanation of the survey and provided verbal consent before data collection. The survey questionnaires were administered by the interviewer. Participants received a gift card to a local store as compensation.

\section{Survey Instrument}

Our survey questionnaire was based on previously used and validated instruments designed for use in the Latino population. To provide continuity and comparison with the 2004 survey, we used the 2004 survey questionnaire with additions regarding an assessment of the exposure to the intervention. Details of the instrument development and the multiple pretests have been previously described. ${ }^{12}$ In training the interview- 
ers for 2008 data collection, we again pretested the questionnaire with Latino community members.

We assessed lifetime experiences with acquisition of antibiotics WORx: antibiotics WORx obtained in a country other than the United States; importation into the United States of antibiotics acquired WORx; and acquisition of antibiotics WORx in the United States. To assess attitudes and behaviors toward self-medication, we evaluated respondents' belief in whether antibiotics WORx should be available in the United States, the future likelihood that a respondent would import antibiotics WORx into the United States, and the acquisition of antibiotics WORx in the United States within the past 12 months. Although the time between the start of the intervention and the evaluation was only 9 months, we believed that because the intervention started in the summer and the evaluation was undertaken in the late spring, asking people to think back over the last year would evaluate peak times for antibiotic use.

Additionally, we asked where and why respondents obtained antibiotics WORx and what illnesses they treated.

\section{Analysis}

We computed $\chi^{2}$ tests to examine potential differences and possible changes pre- and postintervention in Charleston and between Charleston 2008 and Greenville 2008. Because the primary intervention was educational, exposure to appropriate antibiotic-use messages was evaluated for association with attitude toward antibiotics WORx and current antibiotic WORx use. Because of the nonrandomized, community-oriented nature of the design, we evaluated the impact of the intervention through several logistic regressions controlling for potential confounders. We computed a logistic regression with belief in antibiotics available WORx (yes/no) as the dependent variable that included the following independent variables: city (Greenville vs Charleston), exposure to an antibiotic overuse message (yes or no), sex, age, education, insurance (yes or no), education (high school or greater or less than high school), health status (excellent or very good to good, or fair to poor), years in United States, country of birth (Mexico, Caribbean, other), and whether the individual had purchased antibiotics WORx outside the United States. A second logistic regression was computed with the likelihood of importing antibiotics on next trip outside the United States (very likely or likely, neither likely nor unlikely, or unlikely or very unlikely) with the same independent variables specified above. We also computed a logistic regression predicting having gotten antibiotics WORx in the United States in the past 12 months (yes or no) for those who acknowledged ever acquiring antibiotics WORx in the United States. The independent variables included were the same as in the previous regressions.

Because our intervention included Spanish-language newspapers and radio programs, it was difficult to ask individuals whether things they read in the newspaper or heard on the radio were specific to our activities. We did ask about whether individuals had seen our specific Solo Con Receta educational pamphlets. Consequently, we computed additional regressions substituting exposure to Solo Con Receta pamphlets for exposure to any antibiotic overuse message.

\section{RESULTS}

Table 1 displays the characteristics of the community samples. The response rates were $80 \%$ to $85 \%$ (Charleston 2004, 219 of 273; Charleston 2008, 250 of 293; Greenville 2008, 250 of 306). Only respondents with complete data were used for analyses. The majority of respondents have been exposed to messages urging appropriate use of antibiotics whether or not it was our intervention.

Table 2 displays data on the use of antibiotics WORx. More of the Charleston 2008 sample had bought antibiotics WORx in the United States and believed antibiotics WORx should be available.

The results displayed in Table 3 indicate that there is little relationship between exposure to messages educating individuals regarding appropriate use of antibiotics and beliefs that antibiotics should be regulated, likelihood of importing antibiotics, or recent acquisition of antibiotics WORx. This pattern exists across both cities combined and in within-group analyses.

Table 4 displays reasons individuals obtain antibiotics WORx. When asked why antibiotics WORx should not be available, most respondents described the dangers of using antibiotics and the need for medical supervision in their use because of lack of knowledge by laypersons. Only 1 person stated antibiotics WORx should not be available because they are illegal. Many of those that responded that antibiotics should be available WORx mentioned avoiding cost and an ability to rely on past experience or other knowledge for self-diagnosis as reasons. Some respondents also described antibiotics as harmless and described their use as preventive.

Logistic regressions all indicated that the strongest predictor of attitudes toward antibiotics WORx or use of antibiotics WORx in the United States was past purchase of antibiotics WORx outside the United States. The analysis evaluating acquiring antibiotics WORx in the last 12 months showed that after adjustment for other predictor variables, those with less than a high 


\begin{tabular}{|c|c|c|c|}
\hline Characteristic & $\begin{array}{c}\text { Charleston } \\
2004 \\
(n=219) \\
\text { No. }(\%)\end{array}$ & $\begin{array}{c}\text { Charleston } \\
2008 \\
(n=229) \\
\text { No. }(\%)\end{array}$ & $\begin{array}{c}\text { Greenville } \\
2008 \\
(n=243) \\
\text { No. }(\%)\end{array}$ \\
\hline \multicolumn{4}{|l|}{ Country of birth } \\
\hline Mexico & $164(74.9)$ & $78(34.1)$ & $59(24.3)$ \\
\hline Central American country & $24(11.0)$ & $42(18.3)$ & $57(23.4)$ \\
\hline South American country & $24(11.0)$ & $49(21.4)$ & $115(47.3)$ \\
\hline United States & $7(3.2)$ & $19(8.3)$ & $6(2.5)$ \\
\hline Caribbean & - & $41(17.9)$ & $6(2.5)$ \\
\hline Age, mean $\pm S D, y^{c}$ & $29.8 \pm 8.1$ & $35.0 \pm 12.2$ & $35.3 \pm 11.8$ \\
\hline \multicolumn{4}{|l|}{ Health status ${ }^{\mathrm{a}}$} \\
\hline Excellent & $30(13.7)$ & $62(27.1)$ & $56(23.1)$ \\
\hline Very good & $64(29.2)$ & $56(24.4)$ & $71(29.2)$ \\
\hline Good & $96(43.8)$ & $71(31.0)$ & $70(28.8)$ \\
\hline Fair & $22(10.1)$ & $40(17.5)$ & $43(17.7)$ \\
\hline Poor & $7(3.2)$ & $0(0.0)$ & $3(1.2)$ \\
\hline \multicolumn{4}{|l|}{ Sex } \\
\hline Male & 76 (34.7) & $117(51.1)$ & $135(55.6)$ \\
\hline Female & $143(65.3)$ & $112(48.9)$ & $108(44.4)$ \\
\hline \multicolumn{4}{|l|}{ Years in United States } \\
\hline$<1$ & $18(8.2)$ & $6(2.6)$ & $8(3.3)$ \\
\hline $1-3$ & $71(32.4)$ & $39(17.0)$ & $32(13.2)$ \\
\hline $4-6$ & $68(31.1)$ & $72(31.4)$ & $48(19.7)$ \\
\hline$>6$ & $62(28.3)$ & $112(48.9)$ & $155(63.8)$ \\
\hline \multicolumn{4}{|l|}{ Insurance ${ }^{a}$} \\
\hline None & $200(91.3)$ & $156(68.1)$ & $144(59.3)$ \\
\hline Medicaid & $14(6.4)$ & $1(0.4)$ & $1(0.4)$ \\
\hline Other & $5(2.3)$ & $72(31.4)$ & $98(40.3)$ \\
\hline \multicolumn{4}{|l|}{ Education ${ }^{\mathrm{a}}$} \\
\hline Did not graduate from high school & $107(48.9)$ & $54(23.6)$ & 77 (31.7) \\
\hline High school graduate or more & $112(51.1)$ & $175(76.4)$ & $166(68.3)$ \\
\hline \multicolumn{4}{|l|}{$\begin{array}{l}\text { Exposure to some form of appropriate } \\
\text { antibiotic use message }\end{array}$} \\
\hline Print & NA & $132(57.6)$ & $109(44.9)^{b}$ \\
\hline Radio & NA & $96(41.9)$ & $88(36.2)^{\mathrm{b}}$ \\
\hline Print or radio & NA & $158(69.0)$ & $147(60.5)$ \\
\hline $\begin{array}{l}\text { Awareness of exposure to our specific } \\
\text { Solo Con Receta pamphlets }\end{array}$ & NA & $34(25.9)$ & $9(8.6)^{b}$ \\
\hline \multicolumn{4}{|l|}{ NA = not applicable. } \\
\hline \multicolumn{4}{|c|}{$\begin{array}{l}{ }^{a} x^{2} \text { Analysis, Charleston } 2004 \text { significantly different from Charleston } 2008 . \\
{ }^{b} \chi^{2} \text { Analysis, Greenville } 2008 \text { significantly different from Charleston } 2008 . \\
{ }^{c} t \text { Test analysis, Charleston } 2004 \text { significantly different from Charleston } 2008 .\end{array}$} \\
\hline
\end{tabular}

should be available $(\mathrm{OR}=1.95$; 95\% CI, 1.23-3.07). Once again the strongest predictor was past purchase of antibiotics WORx outside the United States $(\mathrm{OR}=2.53$; 95\% CI, 1.69-3.77). The regression analysis evaluating the likelihood of importing antibiotics into the United States showed that those who had been in the United States for fewer than 6 years were more likely to import antibiotics in the future $(\mathrm{OR}=1.64 ; 95 \% \mathrm{CI}$, 1.03 2.62). Similarly, women were more likely than men to report a higher chance of importing antibiotics $(\mathrm{OR}=1.59 ;$ 95\% CI, 1.03-2.45). As with the other 2 regressions, the strongest predictor was past purchase of antibiotics WORx outside the United States (OR = 3.01; 95\% CI, 1.95-4.65).

When we used exposure to our pamphlets rather than exposure to any antibiotic overuse message, the results indicated that exposure to our patient education pamphlets was not a significant predictor of use of antibiotics WORx in the past 12 months $(\mathrm{OR}=0.85 ; 95 \% \mathrm{CI}$, $0.27-2.63)$, or even belief that antibiotics should be available WORx $(\mathrm{OR}=0.58 ; 95 \% \mathrm{CI}, 0.24-1.44)$.

\section{DISCUSSION}

In this evaluation of a communitybased intervention designed to decrease self-medication with antibiotics obtained WORx by adults in the Latino community, the overall results were disappointing.

school education were less likely to have acquired antibiotics WORx $(\mathrm{OR}=0.38$; 95\% CI, 0.18-0.79), and individuals in Charleston were more likely than those in Greenville $(\mathrm{OR}=1.81 ; 95 \% \mathrm{CI}, 1.02-3.22)$ to have acquired them. The strongest predictor was past purchase of antibiotics WORx outside the United States $(\mathrm{OR}=5.72 ; 95 \% \mathrm{CI}, 3.12-10.48)$. No other variables were significant for that regression. When evaluating whether antibiotics WORx should be available, the Charleston sample was more likely to believe they should be available $(\mathrm{OR}=1.60 ; 95 \% \mathrm{CI}, 1.05-2.44)$, and those without insurance were more likely to think they
A substantial proportion of respondents had acquired antibiotics WORx in the United States for self-medication. Although most adults (69.0\%) surveyed in the intervention community had read or heard something on the radio regarding the appropriate use of antibiotics, the exposure did not lead to differences in attitudes toward nonprescription antibiotics or having bought them in the last 12 months. The primary predictor for believing that antibiotics WORx should be available and acquiring antibiotics WORx is the respondent's past behavior of purchasing antibiotics WORx outside the United States. 


\section{Table 2. Use of Antibiotics Without a Prescription}

\begin{tabular}{|c|c|c|c|}
\hline Characteristic & $\begin{array}{l}\text { Charleston } 2004 \\
(n=219) \\
\text { No. }(\%)\end{array}$ & $\begin{array}{l}\text { Charleston } 2008 \\
(n=229) \\
\text { No. }(\%)\end{array}$ & $\begin{array}{c}\text { Greenville } 2008 \\
(n=243) \\
\text { No. }(\%)\end{array}$ \\
\hline \multicolumn{4}{|l|}{ Lifetime use of antibiotics obtained without a prescription } \\
\hline Bought antibiotics without a prescription outside the United States & $99(45.2)$ & $95(41.5)$ & $116(47.7)$ \\
\hline $\begin{array}{l}\text { Imported antibiotics bought outside the United States into the } \\
\text { United States }\end{array}$ & $36(16.4)$ & $28(12.2)$ & $39(16.0)$ \\
\hline Bought antibiotics without a prescription inside the United States & $42(19.2)^{\mathrm{a}}$ & $70(30.6)$ & $48(19.7)^{b}$ \\
\hline $\begin{array}{l}\text { Imported antibiotics or bought antibiotics without a prescription } \\
\text { in United States }\end{array}$ & $67(30.6)$ & $88(38.4)$ & $72(29.6)^{b}$ \\
\hline \multicolumn{4}{|l|}{ Current attitudes or use of antibiotics without a prescription } \\
\hline Believe that antibiotics should be available without a prescription & $67(30.6)^{\mathrm{a}}$ & $110(48.0)$ & $87(35.8)^{b}$ \\
\hline $\begin{array}{l}\text { Bought antibiotics } 1 \text { or more times in the United States without } \\
\text { a prescription in past } 12 \text { months }\end{array}$ & $31(14.2)$ & $43(18.8)$ & $30(12.4)$ \\
\hline $\begin{array}{l}\text { Likelihood very likely or likely of importing antibiotics obtained } \\
\text { without a prescription }\end{array}$ & $52(23.7)$ & $62(27.1)$ & $70(28.8)$ \\
\hline
\end{tabular}

Table 3. Current Attitudes or Use of Antibiotics Without Prescription by Exposure to an Appropriate Antibiotic Use Message

\begin{tabular}{|c|c|c|c|}
\hline \multirow[b]{2}{*}{ Attitude or Use } & \multicolumn{2}{|c|}{ Exposure } & \multirow[b]{2}{*}{$P$ Value } \\
\hline & Yes & No & \\
\hline \multicolumn{4}{|c|}{$\begin{array}{l}\text { Believe that antibiotics should be } \\
\text { available without a prescription, } \%\end{array}$} \\
\hline \multicolumn{4}{|c|}{ Charleston and Greenville 2008} \\
\hline Yes & 40.3 & 44.3 & .40 \\
\hline No & 59.7 & 55.7 & \\
\hline \multicolumn{4}{|l|}{ Charleston 2008} \\
\hline Yes & 45.6 & 53.5 & .26 \\
\hline No & 54.4 & 46.5 & \\
\hline \multicolumn{4}{|l|}{ Greenville 2008} \\
\hline Yes & 34.7 & 37.5 & .66 \\
\hline No & 65.3 & 62.5 & \\
\hline \multicolumn{4}{|c|}{$\begin{array}{l}\text { Bought antibiotics in the United States } \\
\text { without a prescription in past } 12 \text { mo, \% }\end{array}$} \\
\hline \multicolumn{4}{|c|}{ Charleston and Greenville 2008} \\
\hline Yes & 16.4 & 13.8 & .45 \\
\hline No & 83.6 & 86.2 & \\
\hline \multicolumn{4}{|l|}{ Charleston 2008} \\
\hline Yes & 19.0 & 18.3 & .90 \\
\hline No & 81.0 & 81.7 & \\
\hline \multicolumn{4}{|l|}{ Greenville 2008} \\
\hline Yes & 13.6 & 10.4 & .46 \\
\hline No & 86.4 & 89.6 & \\
\hline \multicolumn{4}{|c|}{$\begin{array}{l}\text { Likelihood of importation of antibiotics } \\
\text { obtained without a prescription, } \%\end{array}$} \\
\hline \multicolumn{4}{|c|}{ Charleston and Greenville 2008} \\
\hline Yes & 30.8 & 22.8 & .06 \\
\hline No & 69.2 & 77.2 & \\
\hline \multicolumn{4}{|l|}{ Charleston 2008} \\
\hline Yes & 31.7 & 16.9 & .02 \\
\hline No & 68.3 & 83.1 & \\
\hline \multicolumn{4}{|l|}{ Greenville 2008} \\
\hline Yes & 29.9 & 27.1 & .63 \\
\hline No & 70.1 & 72.9 & \\
\hline
\end{tabular}

These results suggest that usual forms of health education may not be sufficient to overcome the influence of past behavior. Thus, this behavior may be particularly resistant to change. Past research suggests that a patient's past experience in care seeking and treatment use influences future expectations for treatment of respiratory tract infections. ${ }^{15,22,23}$ European countries have grappled with the issue of antibiotic self-medication and found similar factors affecting the likelihood of selfmedication. ${ }^{24}$ They found that a belief in the appropriateness of self-medication with antibiotics and the perceived availability of antibiotics WORx was related to an increased probability of selfmedication. They concluded that interventions aimed at preventing self-medication should include both public education and enforcing regulations regarding sale of antibiotics. An intervention study in Spain, a country with a high degree of antibiotic resistance and self-medication, that included public education and pharmacy oversight was moderately successful over a 5 year period. ${ }^{25}$ 


\begin{tabular}{|c|c|c|c|}
\hline Reason & $\begin{array}{c}\text { Charleston } \\
2004 \\
(n=42) \\
\text { No. }(\%)\end{array}$ & $\begin{array}{c}\text { Charleston } \\
2008 \\
(\mathrm{n}=70) \\
\text { No. }(\%)\end{array}$ & $\begin{array}{c}\text { Greenville } \\
2008 \\
(n=48) \\
\text { No. }(\%)\end{array}$ \\
\hline \multicolumn{4}{|c|}{$\begin{array}{l}\text { Why get antibiotics without a prescription } \\
\text { while inside the United States? }\end{array}$} \\
\hline To avoid a doctor visit & $39(92.9)$ & $55(78.6)$ & $31(64.6)$ \\
\hline Language barrier & $3(7.1)$ & $5(7.1)$ & $3(6.3)$ \\
\hline To avoid a more serious infection & 0 & $4(5.7)$ & $7(14.6)$ \\
\hline Other reasons & 0 & $6(8.6)$ & $7(14.6)$ \\
\hline \multicolumn{4}{|l|}{ Where do you get antibiotics? } \\
\hline From family & $11(26.2)$ & $9(12.9)$ & $6(12.5)$ \\
\hline From friends & $2(4.8)$ & $8(11.4)$ & $6(12.5$ \\
\hline Stores/other sellers & $29(69.1)$ & $53(75.7)$ & $36(75.0)$ \\
\hline \multicolumn{4}{|l|}{$\begin{array}{l}\text { What illness do you treat with these } \\
\text { antibiotics?a }^{\text {? }}\end{array}$} \\
\hline Sore throat & $8(19.1)$ & $26(37.1)$ & $19(39.6)$ \\
\hline Cough & $7(16.7)$ & $5(7.1)$ & $1(2.1)$ \\
\hline Diarrhea & $1(2.4)$ & $2(2.9)$ & 0 \\
\hline Cold & $1(2.4)$ & $7(10.0)$ & $3(6.2)$ \\
\hline Gripe & $15(35.7)$ & $10(14.3)$ & $8(16.7)$ \\
\hline Ear infection & 0 & $8(11.4)$ & $1(2.1)$ \\
\hline Urinary tract infection & 0 & 0 & $3(6.2)$ \\
\hline Dental & 0 & $5(7.1)$ & $2(4.2)$ \\
\hline Other & $10(23.8)$ & $7(10.0)$ & $11(22.9)$ \\
\hline
\end{tabular}

focused on decreasing demand for antibiotics would be sufficient, but it appears that decreasing the supply of antibiotics WORx needs to be an integral part of a comprehensive intervention.

This study has several limitations. First, only Latinos were surveyed, and the message was only given in Spanish. Individuals from other countries where antibiotics are available WORx might have similar patterns of self-medication with antibiotics acquired WORx. ${ }^{23}$ The large recent influx of Latino immigrants and the ease of movement back and forth between Mexico and the United States, however, make Latinos an ideal target group for crafting public health messages to address self-medication with antibiotics.

Second, this study focused on relatively limited strategies to expose the community to the educational message. For example, although we were given hour-long slots on the Spanish language radio station at 2 different times during

The present data are similar to those found in other studies that suggest antibiotic self-medication may not be affected by greater access to care because of the belief that physician consultation is not necessary before treatment. ${ }^{12,13,26}$ Using such strategies as acquiring antibiotics without a prescription from tiendas and pharmacies within the United States does seems to be a cultural artifact of the loosely regulated sale of antibiotics in Latin America. ${ }^{14}$ This practice has appeared in cities with long-standing Latino populations, such as New York City, and occurs in locations, such as Charleston, with a relatively recent influx of Latinos.

Our findings highlight the need to devise effective interventions to deal with self-medication with antibiotics in the Latino community. Education alone may not be enough. Data from New York City indicated that in Latino neighborhoods, as opposed to predominantly non-Hispanic black or non-Hispanic white neighborhoods, antibiotics WORx were remarkably available in the neighborhood stores. ${ }^{14}$ As the Latino community becomes more entrenched, the cultural habits from the home countries are supported by the growing ethnic infrastructure. It may be that a greater focus on regulation of the selling of antibiotics WORx is necessary. Our hypothesis was that an intervention the 9-month intervention to talk about the dangers of self-medication with antibiotics, 2 hours would not be considered an intense educational intervention for many in the community. Further, even though only a minority of individuals acknowledged seeing our pamphlets for Solo Con Receta, most individuals in Charleston acknowledged being exposed at some point to a judicious antibiotic use message.

Third, the intervention was relatively short-lived to see a substantial change in behavior. The intervention only covered 1 primary season for illness. Future interventions may benefit from longer periods.

Fourth, although we pretested the pamphlets on a group of Latinos before introduction of the intervention, we did not formally assess the literacy level of the study population. Thus, the materials may have been written at too high a level to be understood by the community.

Fifth, our samples were composed of Latinos from different countries of origin. Although past studies suggest that Latinos from different countries of origin and individuals from countries where antibiotics are available WORx in general tend to be higher in selfmedication, these origin differences may have affected their beliefs and behavior. ${ }^{13,15,24,26,27}$ 
Finally, the increased use of antibiotics in the intervention community compared with the control community may have resulted in the intervention actually increasing the awareness of the availability of antibiotics without a prescription in the intervention community and subsequently given rise to higher antibiotic usage.

In conclusion, interventions are necessary to promote the appropriate use of antibiotics in the Latino community in the United States. Successful interventions may need to incorporate education about the rationale for why antibiotics are regulated in the United States.

To read or post commentaries in response to this article, see it online at http://www.annfammed.org/cgi/content/full/7/6/520.

Submitted January 26, 2009; submitted, revised, March 30, 2009; accepted April 17, 2009.

Key words: Hispanic Americans; self-medication; antibacterial agents; respiratory tract infections

Funding support: Funded in part by the Blue Cross-Blue Shield Foundation of South Carolina, and the Robert Woods Johnson Foundation.

Acknowledgments: Special thanks to Judith Rundebaker and Magdaly Volcko for their work as interviewers, and Dixie Roberts at the South Carolina Department of Health and Environmental Control for printing of the patient education pamphlets.

\section{References}

1. Spellberg B, Guidos R, Gilbert D, et al for the Infectious Diseases Society of America. The epidemic of antibiotic-resistant infections: a call to action for the medical community from the Infectious Diseases Society of America. Clin Infect Dis. 2008;46(2):155-164.

2. Smolinski MS, Hamburg MA, Lederberg J. Microbial Threats to Health: Emergence, Detection, and Response. Washington, DC: Institute of Medicine; 2003.

3. Infectious Diseases Society of America. Bad Bugs, No Drugs: As Antibiotic Discovery Stagnates, A Public Health Crisis Brews. Alexandria, VA: Infectious Diseases Society of America; 2004.

4. Sarkar P, Gould IM. Antimicrobial agents are societal drugs: how should this influence prescribing? Drugs. 2006;66(7):893-901.

5. Neu HC. The crisis in antibiotic resistance. Science. 1992;257(5073): 1064-1073.

6. Cohen ML. Epidemiology of drug resistance: implications for a post-antimicrobial era. Science. 1992;257(5073):1050-1055.

7. Becker J, Drucker E, Enyong P, Marx P. Availability of injectable antibiotics in a town market in southwest Cameroon. Lancet Infect Dis. 2002;2(6):325-326.

8. Hsueh P-R, Luh K-T. Antimicrobial resistance in Streptococcus pneumoniae, Taiwan. Emerg Infect Dis. 2002;8(12):1487-1491.
9. Dua V, Kunin CM, White LV. The use of antimicrobial drugs in Nagpur, India. A window on medical care in a developing country. Soc Sci Med. 1994;38(5):717-724.

10. Calva J, Bojalil R. Antibiotic use in a periurban community in Mexico: a household and drugstore survey. Soc Sci Med. 1996;42(8): 1121-1128.

11. Drug Utilization Research Group. Latin America. Multicenter study on self-medication and self-prescription in six Latin American countries. Clin Pharmacol Therapuetics. 1997;61:488-493.

12. Mainous AG III, Cheng AY, Garr RC, Tilley BC, Everett CJ, McKee MD. Nonprescribed antimicrobial drugs in Latino community, South Carolina. Emerg Infect Dis. 2005;11(6):883-888.

13. Mainous AG III, Diaz VA, Carnemolla M. Factors affecting Latino adults' use of antibiotics for self-medication. J Am Board Fam Med. 2008;21(2):128-134.

14. Larson E, Grullon-Figueroa L. Availability of antibiotics without prescription in New York City. J Urban Health. 2004;81(3):498-504.

15. Larson EL, Dilone J, Garcia M, Smolowitz J. Factors which influence Latino community members to self-prescribe antibiotics. Nurs Res. 2006;55(2):94-102.

16. Rabinowitz PM, Sircar KD, Tarabar S, Galusha D, Slade MD. Hearing loss in migrant agricultural workers. J Agromedicine. 2005;10(4):9-17

17. Quandt SA, Arcury TA, Early J, Tapia J, Davis JD. Household food security among migrant and seasonal latino farmworkers in North Carolina. Public Health Rep. 2004;119(6):568-576.

18. Arcury TA, Quandt SA, Austin CK, Preisser J, Cabrera LF. Implementation of EPA's Worker Protection Standard training for agricultural laborers: an evaluation using North Carolina data. Public Health Rep. 1999;114(5):459-468.

19. Ward MH, Prince JR, Stewart PA, Zahm SH. Determining the probability of pesticide exposures among migrant farmworkers: results from a feasibility study. Am J Ind Med. 2001;40(5):538-553.

20. McCurdy SA, Samuels SJ, Carroll DJ, Beaumont JJ, Morrin LA. Agricultural injury in California migrant Hispanic farm workers. Am J Ind Med. 2003;44(3):225-235.

21. Varela-Ramirez A, Mejia A, Garcia D, Bader J, Aguilera RJ. HIV infection and risk behavior of Hispanic farm workers at the west Texas-Mexico border. Ethn Dis. 2005;15(4 suppl 5):S5-92-96.

22. Mainous AG III, Zoorob RJ, Oler MJ, Haynes DM. Patient knowledge of upper respiratory infections: implications for antibiotic expectations and unnecessary utilization. J Fam Pract. 1997;45(1):75-83.

23. McKee MD, Mills L, Mainous AG III. Antibiotic use for the treatment of upper respiratory infections in a diverse community. J Fam Pract. 1999;48(12):993-996.

24. Grigoryan L, Burgerhof JG, Degener JE, et al for the Self-Medication with Antibiotics and Resistance (SAR) Consortium. Determinants of self-medication with antibiotics in Europe: the impact of beliefs, country wealth and the healthcare system. J Antimicrob Chemother. 2008;61(5):1172-1179.

25. Gastelurrutia MA, Larranga B, Ortega B. Primer programa institucional de uso racional de antibioticos en Gipuzkoa: evaluacion de los anos 1999-2004. Pharmacy Pract (Granada Ed. Impr). 2006;4:1-8.

26. Coffman MJ, Shobe MA, O'Connell B. Self-prescription practices in recent Latino immigrants. Public Health Nurs. 2008;25(3):203-211.

27. Berzanskyte A, Valinteliene R, Haaijer-Ruskamp FM, Gurevicius R, Grigoryan L. Self-medication with antibiotics in Lithuania. Int J Occup Med Environ Health. 2006;19(4):246-253. 